\title{
Dihydropteridine reductase activity in dried blood spots: effects of aging and senile dementia of the Alzheimer type
}

\author{
CATHERINE M JEEPS, ANNE SILCOX, BARBARA LLOYD, \\ BARBARA E CLAYTON
}

From the University Department of Chemical Pathology, and Human Metabolism, University of Southampton, Southampton General Hospital, Southampton

SUMMARY Dihydropteridine reductase (EC 1.6.99.7) (DHPR) activity was measured in blood spots from 50 neonates, 52 healthy adults aged 30-62 years, and 21 elderly controls aged 67-97 years, as well as 32 demented patients of whom 25 had senile dementia of the Alzheimer type. Enzyme activity was stable for seven days at $4^{\circ} \mathrm{C}$ and for at least 14 days at $-20^{\circ} \mathrm{C}$. No important difference was found between the DHPR activity of venous and capillary blood. DHPR activity was considerably lower in the healthy adult group compared with neonates and the elderly group, and there was no sex difference at any age. The erythrocyte DHPR activity of patients with senile dementia of the Alzheimer type was similar to that of elderly controls. This result differs from that previously reported for leucocytes.

It has been estimated that by the end of the century some 60 million people will suffer from senile dementia of the Alzheimer type. ${ }^{1}$ Many aetiological hypotheses have been suggested-for example, neurotoxic factors, ${ }^{23}$ a virus, ${ }^{4}$ autoimmune disease, ${ }^{5}$ and genetic factors. ${ }^{6}$

The study of neurochemistry senile dementia in the Alzheimer type seems to be a more hopeful approach with regard to future treatment. Reduced concentrations of choline acetyltransferase activity, ${ }^{7-10}$ noradrenaline, ${ }^{11} 12$ dopamine, ${ }^{13}$ dopamine-Bhydroxylase activity, ${ }^{14}$ homovanillic acid, ${ }^{15}$ 5-hydroxytryptamine, 5 -hydroxy indole acetic acid, ${ }^{11}$ and somatostatin ${ }^{9}$ have all been reported. The neurochemical deficiencies seem to be greater than can be accounted for simply by cell death caused by dementia. ${ }^{16}$

Tetrahydrobiopterin $\left(\mathrm{BH}_{4}\right)$ is the essential cofactor for the formation of dopamine, noradrenaline, adrenaline, and 5-hydroxytrytophan from phenylalanine, tyrosine, and tryptophan, respectively.$^{17-20}$ Interest in the neurological role of biopterins was first stimulated by the description of three children with a variant form of phenylketonuria. Despite early diagnosis and dietetic treatment they developed severe neu-

Accepted for publication 31 October 1985 rological dysfunction. Biochemical lesions, later established as causative in this condition, include dihydropteridine reductase (DHPR) (EC 1.6.99.7) deficiency and defective synthesis of $\mathrm{BH}_{4}$ with normal DHPR activity. ${ }^{21-23}$ The resulting deficiencies of neurotransmitters respond to replacement treatment both with neurotransmitters and intravenous $5,6,7,8$ tetrahydrobiopterin ${ }^{24}$.

Disturbed $\mathrm{BH}_{4}$ metabolism has been described in several neurological diseases including senile dementia of the Alzheimer type, in which decreased biopterin concentrations have been reported in serum, ${ }^{25} 26$ plasma, ${ }^{27}$ and cerebrospinal fluid. ${ }^{28} 29$ In addition, decreased synthesis of $\mathrm{BH}_{4}$ has been shown in the temporal lobe samples removed from patients with senile dementia of the Alzheimer type at necropsy. ${ }^{30}$ Neopterin (a precursor of $\mathrm{BH}_{4}$ ) concentrations in dementia are no different from those in healthy control subjects, and this would support the concept that deficiency is not merely due to cell death.

The reason for reduced $\mathrm{BH}_{4}$ in senile dementia of the Alzheimer type and other neurological diseases is as yet unknown. In samples from temporal lobe brain DHPR activity of patients dying with senile dementia of the Alzheimer type was not greatly different from that of controls. ${ }^{30}$ Considerably lowered values of DHPR have, however, been shown in the leucocytes 
of patients with senile dementia of the Alzheimer type compared with those in healthy elderly controls. ${ }^{27}$ The success of $\mathrm{BH}_{4}$ treatment in children with variant phenylketonuria and thus the possibility of similar treatment of patients with senile dementia of the Alzheimer type indicates the need for further investigation of biopterin metabolism in dementia. The objective of this study was to determine the effect of age on DHPR reductase activity in erythrocytes and whether the values were changed in senile dementia of the Alzheimer type.

The project was approved by the Joint Ethical Sub Committee of the Faculty of Medicine of the University of Southampton and Southampton and South West Hampshire Health Authority.

\section{Material and methods}

\section{SUBJECTS AND CONTROLS}

Group 1 neonates Capillary blood samples collected on to Guthrie cards for routine screening from 50 neonates between the sixth and 11th day of life were assayed for DHPR activity. No neonate had hyperphenylalaninaemia.

Group 2 healthy adults Venous blood samples $(1 \mathrm{ml})$ were collected from 26 men and 26 women aged 30 to 62 years. With the exception of two women taking oral contraceptives, no volunteer was receiving medication.

Group 3 elderly adults Venous blood was collected from 31 patients aged 67 to 97 years attending a day hospital. This group, comprising 21 women and 10 men with scores of 25 or more on mental test assessment, ${ }^{31}$ was used as a control for comparison with the group with dementia. These patients had various conditions and were almost all receiving multidrug treatment.

Group 4 demented patients Venous blood was obtained from 32 demented patients aged between 69 and 87 years. They were divided into subgroups according to the clinical diagnosis and the Hachinski score, which acts as an indicator of multi-infarct dementia. ${ }^{32}$ Four had computed tomography brain scans to aid difficult diagnosis. Patients with secondary causes of dementia were excluded. All of them were receiving multidrug treatment.

6-methyl-5,6,7,8-tetrahydrobiopterin, ferricytochrome $\mathrm{C}$ type III from horse heart, and nicotinamide adenine dinucletide (reduced form) were obtained from Sigma. All other chemicals were of Analar grade and obtained from BDH. Filter paper (grade 31 ET CHROMA) was obtained from Whatman Chemical Separation.

A Pye Unicam SP1800 double beam spectrophotometer set at a wavelength of $550 \mathrm{~nm}$ and a Pye
Unicam AR 25 linear recorder were used to monitor the change in absorbance at $37^{\circ} \mathrm{C}$.

\section{PROCEDURES}

The activity of DHPR was determined by the method of Arai et $a l,{ }^{33}$ modified to increase sensitivity by $\frac{\bar{\sigma}}{\bar{\omega}}$ doubling the concentration of ferricytochrome $\mathbf{C}$ and $\vec{\nabla}$ increasing the temperature of the reaction to $37^{\circ} \mathrm{C}$. $\cong$ Using the modified assay conditions, it was necessary to confirm that the erythrocyte DHPR activity was $\overrightarrow{0}$ still proportional to the concentration of haemoglobin up to $0.5 \mathrm{mg} / \mathrm{ml}$. Venous blood was diluted $\vec{\omega}$ with distilled water to give a haemoglobin concentration range of $0.05-1.6 \mathrm{mg} /$ cuvette. The DHPR activity at each haemoglobin concentration was $\omega_{0}$ measured. The diluted samples were then centrifuged iv at $2000 \mathrm{rpm}$ for 10 minutes, and the DHPR activity $\vec{\bullet}$ for each sample was assayed again using the supernatants.

A DHPR assay for use with blood spot samples $\vec{T}$ would provide the most effective method for screen- $\mathbb{D}$ ing of the elderly. For this reason and also to standardise the procedure for the neonatal and adult samples all the venous blood samples were spotted on to filter paper before analysis. It was therefore necessary $\ddot{\oplus}$ to compare enzyme activity in capillary blood with that of venous blood. Both types of sample were collected from each of five healthy volunteers, and DHPR activity was measured in all the samples.

In addition, the whole blood samples and capillary blood spots were stored at $4^{\circ} \mathrm{C}$ and $-20^{\circ} \mathrm{C}$ and subsequently analysed to determine the stability of the enzyme. Intrabatch precision was determined by analysing 18 replicate samples and interbatch precision was calculated from six analyses for three subjects.

\section{Results}

The Figure shows that at haemoglobin concen-

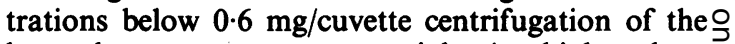
haemolysate was not essential. At higher hae- $>$ moglobin concentrations the relation with DHPR을 activity was non-linear. Failure to remove red cell $\bar{N}$ membranes led to an apparent further reduction in DHPR activity. As this was a potential source of 0 error, care was taken to ensure that each haemolysate $N$ was centrifuged and that the haemoglobin concentration was below $0.6 \mathrm{mg} /$ assay.

Using a paired $t$ test no significant differences were $\frac{0}{\odot}$ found between DHPR activity in capillary or venous $\stackrel{?}{+}$ blood samples. Whole blood samples and blood spots 0 were stable for seven days at $4^{\circ} \mathrm{C}$ and for at least two weeks at $-20^{\circ} \mathrm{C}$. The results for intrabatch precision were mean $=3.68((\mathrm{SD}) 0.22)$ with a coefficient of 


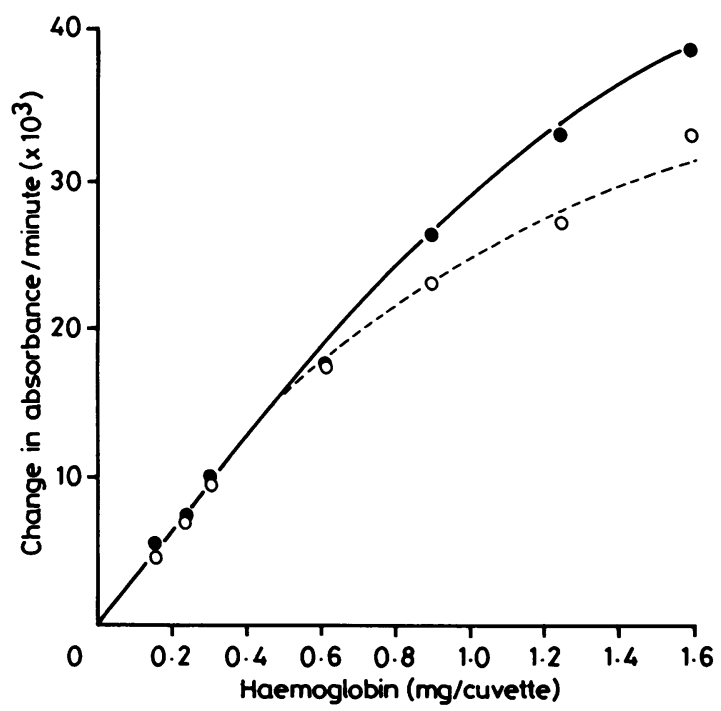

Effect of haemoglobin concentration on erythrocyte DHPR activity

variation of $6.0 \%$. The coefficient of variation for the interbatch precision, however, varied from $8.6 \%$ to $10 \cdot 2 \%$.

The Table gives the results of enzyme activity in the four groups. There was no sex difference in any group. Enzyme activity was higher in groups 1 and 3 when compared with that of group 2. On further subdivision of group 2 by age (Table), using nonparametric analysis, the results of those aged 40 to 49 years were higher than for those aged 30 to 39 years and significantly higher than for those aged 50 to 62 years $(p<0 \cdot 05)$. Group 3 was also divided into subgroups by age, but no difference in enzyme activity was observed, nor was enzyme activity associated with the mental test score. Patients with senile dementia of the Alzheimer type had the same enzyme activ- ity as those in group 3 . The seven patients with other types of dementia seemed to have similar values.

\section{Discussion}

The method used for the DHPR assay was simple, sensitive, and precise. The observed adult control range of DHPR activity was greater than that reported by Arai et al, ${ }^{33}$ and this may be due to the higher temperature used in the analysis.

There was no direct correlation of enzyme activity with age. Patients in group 2 showed lower activity than those in groups 1 and 3 . It is unlikely that the increased values in group 3 (compared with group 2) were due to a simple age effect. The probable causes include multipathology and the effects of drugs. The commonest types of drug taken by the elderly patients in this study were tricyclic antidepressants, benzodiazepines, non-steroidal anti-inflammatory analgesics, diuretics, and cardiac glycosides. Tricyclic antidepressants and phenothiazines produce no effect on lymphocyte DHPR activity in vivo. ${ }^{27}$ In vitro studies have concluded that tricyclic antidepressants, diazepam, chlorpromazine, trimethoprim, and sulphamethoxazole have no effect on DHPR and that methotrexate, librium, folic acid, and ferrous sulphate inhibit the enzyme. ${ }^{34}$ The effects of multipathology, however, together with combined drug treatment on DHPR activity have yet to be defined.

Interestingly, when group 2 was subdivided, those aged $40-49$ years seemed to have higher values. There were more women in this subgroup, and perhaps the menopause affects erythrocyte DHPR activity.

There was no reduction in erythrocyte DHPR activity in patients with senile dementia of the Alzheimer type when compared with non-demented patients of similar age. This contrasts with the decreased DHPR in lymphocytes of patients with senile dementia of the Alzheimer type reported pre-

Erythrocyte DHPR activities (mean (SD))

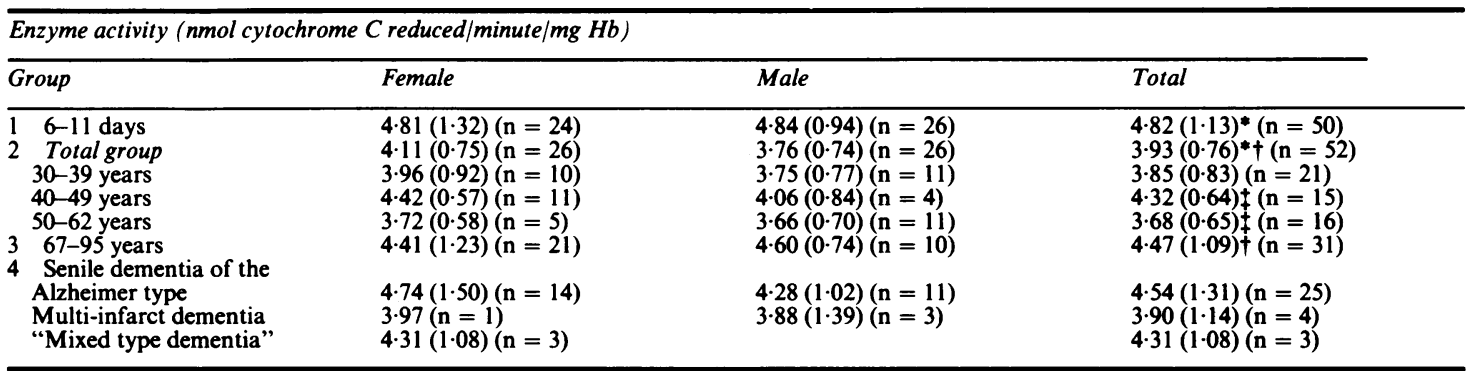

*p $<0.05$ group 2 compared with group 1;

tp $<0.05$ group 2 compared with group 3;

$\ddagger p<0.05$ age group 40-49 years compared with age group 50-62 years. 
viously. ${ }^{27}$ The methods used in both studies were similar. The DHPR assay on dried blood spots, however, is more precise than that for lymphocytes, with an interassay coefficient of variation of $9-10 \%$, compared with $24 \%$ for the lymphocyte assay. It is possible that neither lymphocyte nor erythrocyte DHPR values reflect the enzyme's activity within the brain, but evidence suggests that this is not the case. Analysis of DHPR in leucocytes, erythrocytes, liver, brain, and skin from patients clinically diagnosed as having malignant hyperphenylalaninaemia, all showed a total enzyme deficiency. ${ }^{22} 3335$ In addition, DHPR in human liver, leucocytes, erythrocytes, and fibroblasts has similar immunochemical characteristics. ${ }^{33}{ }^{35}$ An alternative explanation, therefore, should be sought. Other clinical conditions and the medication of the elderly patients may have had important influences on DHPR activity and could account for the differing study results. A recent report showed that the neurotransmitter deficit in younger patients with senile dementia of the Alzheimer type dying in their seventh and eighth decades was more widespread and severe than that of the older patients with this condition. ${ }^{36}$ Separating the data from this study-those under 80 years of age and those who were older-showed no difference in DHPR activity between the groups. It is impossible to draw conclusions from the other groups with dementia we studied due to the small number of samples analysed. All the results seemed to fall within the observed range for the elderly control patients, suggesting that there is no obvious DHPR deficit in multi-infarct and mixed type dementia.

It has been suggested that there is a defect in the synthesis of $\mathrm{BH}_{4}$ in senile dementia of the Alzheimer type. ${ }^{2627}$ Brains from subjects with senile dementia of the Alzheimer type have lowered total biopterin concentrations but retain their ability to synthesise neopterin and have normal DHPR activity. ${ }^{30}$ This indicates a specific loss of ability to convert dihydroneopterin triphosphate to $\mathrm{BH}_{4}$ during de novo biosynthesis. The normal erythrocyte DHPR activity shown in the group with senile dementia of the Alzheimer type in this study supports these findings, and, as suggested previously, ${ }^{27}$ indicates a possible therapeutic role for $\mathrm{BH}_{4}$ in this disease.

We thank Drs RSJ Briggs and TI Reid for permission to study their patients; Dr G Prasad for collection of blood samples and patient data at Moorgreen Day Hospital; and Miss A Symons for collection of blood samples and information from the subjects in the groups with dementia. We also thank Dr G Batstone for permission to use Guthrie card blood spots, as well as all the healthy volunteers who made this study possible. Finally, we thank the Mental Health Foundation for their financial support.

\section{References}

1 Besson J. Dementia: biological solution still a long way off. $\mathrm{Br} \mathrm{Med}$ $J$ 1983;287:926-7.

${ }^{2}$ Crapper DR, Krishnan SS, Dalton AJ. Brain aluminium distribution in Alzheimer's disease and experimental neurofibrillary degeneration. Science 1973;180:511-3.

${ }^{3}$ Alfrey AC, Le Gendre GR, Kaehny WD. The dialysis encephalopathy syndrome-possible aluminium intoxication. $N$ Engl $J$ Med 1976;294:184-8.

${ }^{4}$ Schneck MK, Reisberg B, Ferris SH. An overview of current concepts of Alzheimer's disease. Am J Psychiatry 1982;139:165-73.

${ }^{5}$ Tkach JR, Hokama Y. Autoimmunity in chronic brain syndrome: a preliminary report. Arch Gen Psychiatry 1970;23:61-4.

${ }^{6}$ Smith GF, Berg JM. Down's Anomaly. 2nd ed. Edinburgh: Churchill Livingstone, 1976:62.

${ }^{7}$ Perry EK, Tomlinson BE, Blessed G, Bergman K, Gibson PH, Perry RH. Correlation of cholinergic abnormalities with senile plaques and mental test scores in senile dementia. $\mathrm{Br} \mathrm{Med} J$ 1978;ii:1457-9.

${ }^{8}$ Davies P, Maloney AJF. Selective loss of central cholinergic neurons in Alzheimer's disease. Lancet 1976;ii:1403.

${ }^{9}$ Davies P, Katzman R, Terry RD. Reduced somatostatin-like immunoreactivity in cerebral cortex from cases of Alzheimer disease and Alzheimer senile dementia. Nature 1980;288:279-80.

${ }^{10}$ Coyle JT, Price DL, DeLong MR. Alzheimer's disease: a disorder of cortical cholinergic innervation. Science 1983;219:1184-90.

${ }^{11}$ Gottfries CG. The metabolism of some neurotransmitters in ageing and dementia disorders. Gerontology 1982;2 (suppl):11-9.

${ }^{12}$ Mann DMA, Lincoln J, Yates PO, Stamp JE, Toper S. Changes in the monoamine containing neurones of the human CNS in senile dementia. Br J Psychiatry 1980;136:533-41.

${ }^{13}$ Adolfsson R, Gottfries CG, Roos BE, Winblad B. Changes in brain catecholamines in patients with dementia of Alzheimer type. Br J Psychiatry 1979;135:216-23.

${ }^{14}$ Cross AJ, Crow TJ, Perry EK, Perry RH, Blessed G, Tomlinson BE. Reduced dopamine-beta-hydroxylase activity in Alzheimer's disease. $\mathrm{Br}$ Med J 1981;282:93-4.

15 Gottfries CG, Gottfries I, Roos BE. The investigation of homovanillic acid in the human brain and its correlation to senile dementia. Br J Pyschiatry 1969;115:563-74.

${ }^{16}$ Bowen DM, Spillane JA, Curzon G, et al. Accelerated ageing or selective neuronal loss as an important cause of dementia. Lancet 1979; i:11-4.

${ }^{17}$ Kaufman S, Levenberg B. Further studies on the phenylalanine hydroxylation co-factor. $J$ Biol Chem 1959;234:2683-8.

${ }^{18} \mathrm{Kaufman} \mathrm{S}$. A new cofactor required for the enzymatic conversion of phenylalanine to tyrosine. J Biol Chem 1958;230:931-9.

${ }^{19}$ Brenneman AR, Kaufman S. The role of tetrahydropteridines in the enzymatic conversion of tyrosine to 3,4-dihydroxyphenylalanine. Biochem Biophys Res Commun 1964;17:177-83.

${ }^{20}$ Hosoda S, Glick D. Properties of tryptophan hydroxylase from neoplastic murine mast cells. J Biol Chem 1966;241:192-6.

${ }^{21}$ Smith I, Clayton BE, Wolff OH. New variant of phenylketonuria with progressive neurological illness unresponsive to phenylalanine restriction. Lancet 1975;i:1108-11.

${ }^{22}$ Kaufman S, Holtzman NA, Milstien S, Butler IJ, Krumholz A. Phenylketonuria due to a deficiency of dihydropteridine reductase. N Engl J Med 1975;293:785-90.

${ }^{23}$ Danks DM, Bartholome K, Clayton BE, et al. Malignant hyperphenylalaninaemia-current status (June 1977). Journal of Inherited Metabolic Disease 1978;1:49-53.

${ }^{24}$ Danks DM, Cotton RGH, Schlesinger P. Tetrahydrobiopterin treatment of variant form of phenylketonuria. Lancet 1975;ii: 1043.

${ }^{25}$ Aziz AA, Leeming RJ, Blair JA. Tetrahydrobiopterin metabolism 
in senile dementia of the Alzheimer type. $J$ Neurol Neurosurg Psychiatry 1983:46:410-13.

${ }^{26}$ Leeming RJ, Blair JA, Melikian V. Biopterin derivatives in senile dementia. Lancet 1979;i:215.

${ }^{27}$ Young JH, Kelly B. Clayton BE. Reduced levels of biopterin and dihydropteridine reductase in Alzheimer-type dementia. Journal of Clinical Experimental Gerontology 1982:4:389-402.

${ }^{28}$ Morar C, Whitburn SB, Blair JA, Leeming RJ, Wilcock GK. Tetrahydrobiopterin metabolism in senile dementia of the Alzheimer type. J Neurol Neurosurg Psychiatry 1983;46:582-90.

${ }^{29}$ Williams AC, Levine RA, Chase TN, Lovenberg W, Calne DB. CSF hydroxylase cof actor levels in some neurological diseases. $J$ Neurol Neurosurg Psychiatry 1980:43:735-8.

${ }^{30}$ Barford PA. Blair JA, Eggar C, Hamon C, Morar C, Whitburn SB. Tetrahydrobiopterin metabolism in the temporal lobe of patients dying with senile dementia of Alzheimer type. $J$ Neurol Neurosurg Psychiatry 1984;47:736-8.

${ }^{31}$ Blessed G, Tomlinson BE, Roth M. The association between quantitative measure of dementia and seniie changes in cerebral grey matter of elderly subjects. $B r J$ Psychiatry 1968; 114:797-811.

${ }^{32}$ Hachinski VC. Iliff LD, Zilka E. et al. Cerebral blood flow in dementia. Arch Neurol 1975;32:632-7.

${ }^{33}$ Arai N, Narisawa K, Hayakawa H, Tada K. Hyperphenylalaninaemia due to dihydropteridine reductase deficiency: diagnosis by enzyme assays on dried blood spots. Paediatrics 1982;70:426-30.

${ }^{34}$ Leeming RJ. Metabolism of biopterin and its derivatives in man and the rat. Birmingham: University of Aston, 1979:64-83. (PhD thesis).

${ }^{35}$ Narisawa K, Aria N, Ishizawa S, et al. Dihydropteridine reductase deficiency: diagnosis by leucocyte enzyme assay. Clin Chim Acta 1980;105:335-42.

${ }^{36}$ Rossor MN, Iversen LL, Reynolds GP, Mountjoy CQ, Roth M. Neurochemical characteristics of early and late onset types of Alzheimer's disease. Br Med J 1984;288:961-4.

Requests for reprints to: Mrs Barbara Lloyd, Room LD 62, South Laboratory \& Pathology Block, Southampton General Hospital, Tremona Road, Southampton SO9 4XY, England. 